\title{
Endometrial Adenocarcinoma with Concomitant Left Atrial Myxoma
}

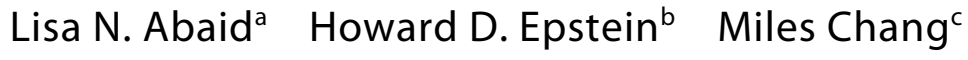 \\ Rita Kankus ${ }^{\mathrm{a}}$ Bram H. Goldstein ${ }^{\mathrm{a}}$ \\ ${ }^{a}$ Gynecologic Oncology Associates, Hoag Cancer Center, Departments of \\ ${ }^{b}$ Pathology and 'Radiology, Hoag Memorial Hospital Presbyterian, Newport \\ Beach, Calif., USA
}

\section{Key Words}

Endometrial cancer · Atrial myxoma $\cdot$ Co-morbidity $\cdot$ Diagnosis $\cdot$ Treatment

\begin{abstract}
Background: Atrial myxomas are the most common primary heart tumors and predominantly considered to be benign lesions.

Case Study: We report a case involving a 77-year-old woman who presented with a pelvic mass. She was found to have a primary endometrial cancer and primary lung cancer with concomitant metastatic adrenal gland and mesenteric lesions. Her prior medical history also included an untreated $4.0 \times 2.0-\mathrm{cm}$ left atrial myxoma which was identified on $\mathrm{CT}$ scan during the workup of her pelvic mass.

Results: A clinical decision was made to proceed with surgery for the pelvic mass with a subsequent recommendation for left atrial mass resection. Currently, the patient is scheduled to begin chemotherapy for primary lung cancer.

Conclusion: The reported incidence of uterine cancer and a concurrent atrial myxoma is very rare. Consequently, the manner and timing in which treatment should be provided is imprecise. In the present case, the risk for cardiac complications was high, but given the presence of a partial bowel obstruction and the need to diagnose the primary site of her metastatic malignancy, the decision was made to proceed with exploratory abdominal surgery.
\end{abstract}

\section{Introduction}

Atrial myxomas are the most common primary heart tumors, accounting for $40-50 \%$ of primary cardiac tumors $[1,2]$. However, the lifetime risk of developing an atrial myxoma is approximately $0.02 \%$ [3]. Primarily, these lesions are benign, localized and 
identified within the left atrium. Moreover, atrial myxomas are predominantly quiescent, sporadic and discovered as an incidental finding in nearly $20 \%$ of cases [4].

Conditions associated with atrial myxomas include mitral stenosis, endocarditis, mitral regurgitation, and collagen vascular disease $[5,6]$. Clinically, patients may experience fatigue, dyspnea, angina pectoris and congestive heart failure from obstructed mitral or tricuspid valvular blood flow. Studies have also indicated that in approximately $15 \%$ of atrial myxoma cases, mechanical, valvular heart failure may develop $[7,8]$. When cardiac death occurs, the event is often attributed to a coronary embolization or a compromised (e.g., elderly) health condition.

Currently, there is scant documentation involving the treatment for an atrial myxoma in the context of a recently diagnosed primary uterine cancer [9]. There have been studies involving a uterine leiomyoma or leiomyosarcoma either mimicking an atrial myxoma $[10]$ or infiltrating the atrium $[11,12]$, but there have been virtually no clinical cases in which an endometrial adenocarcinoma and an atrial myxoma were managed concurrently [9]. We report herein the history and complicated treatment of a patient affected by these two conditions.

\section{Case Report}

A 77-year-old (gravida 3, para 3) female presented with a pelvic mass and a partial small bowel obstruction in April 2009. She underwent a CT scan of the abdomen and pelvic in the emergency room which identified the pelvic lesion in addition to a $6-\mathrm{cm}$ mesenteric mass and a $5-\mathrm{cm}$ left adrenal mass. She had no vaginal bleeding. Furthermore, a large lesion was identified in the left atrium, which in retrospect was visible on an abdominal CT scan obtained in 2005. The cardiac mass (fig. 1) was unchanged between 2005 and 2009. The patient had no cardiac history and was asymptomatic from the mass, which was suspected to be a mural thrombus. Her prior medical history included Staph cellulitis and acute bronchitis.

The cardiac mass was evaluated with transesophageal echocardiogram and was found to be a $4-\mathrm{cm}$ polypoid lesion originating in the left atrium, which prolapsed across the mitral valve into the left ventricle with each heartbeat. Although a biopsy was not performed, the location, appearance, and stability supported a diagnosis of atrial myxoma.

Following cardio-thoracic consultation, prompt open heart surgery with atrial mass resection was strongly considered. However, given that the cardiac lesion was symptom-free since 2005 and there were immediate concerns regarding a presumed metastatic malignancy and the potential development of a complete bowel obstruction, proceeding with abdominal surgery was recommended.

Prior to the initiation of abdominal surgery, the patient was cleared by cardiology and cardiothoracic surgery. Continuous cardiac monitoring during the surgery was employed with a trans-esophageal echocardiogram to monitor cardiac function. The patient was aggressively hydrated as the risk of acute occlusion of the mitral valve by the mass was felt to be increased in the setting of intravascular volume depletion.

Surgical findings included an enlarged, globoid uterus with no intraperitoneal tumor. The omentum was free of disease and the retroperitoneal pelvic and para-aortic lymph nodes were not enlarged. A 6$\mathrm{cm}$ bulky tumor was found at the root of the mesentery in the proximal jejunum and this was resected along with $23 \mathrm{~cm}$ of small bowel. The adrenal mass was palpated, found to be minimally mobile, and was not resected. An infracolic omentectomy was also performed.

Frozen section of the uterus at the time of surgery revealed primary endometrial cancer and frozen section of the mesenteric mass was thought to be consistent with metastatic endometrial cancer (fig. 2). However, on final pathology the mesenteric mass was identified as a poorly differentiated carcinoma, immunohistochemically distinct from the uterine carcinoma, and consistent with a pulmonary or gastrointestinal primary (fig. 3 ).

Postoperatively, the patient underwent a mammogram, colonoscopy and upper GI endoscopy, which were normal. A subsequent PET scan exhibited mediastinal adenopathy and this, combined with 


\begin{tabular}{|c|c|c|c|}
\hline $\begin{array}{c}\text { Case Reports in } \\
\text { Ence.ail }\end{array}$ & $\begin{array}{l}\text { Case Rep Oncol 2009;2:150-156 } \\
\text { DOI: 10.1159/000231995 }\end{array}$ & Published online: August 20, 2009 & \begin{tabular}{|l} 
@ 2009 S. Karger AG, Basel \\
ISSN 1662-6575 \\
www.karger.com/cro
\end{tabular} \\
\hline
\end{tabular}

the immunohistochemical stains, the pattern of metastatic spread, and the patient's extensive smoking history, supports a primary lung cancer.

\section{Conclusion}

Endometrial cancer is the fourth most frequent cause of cancer in US women, accounting for nearly 7,470 deaths in 2008 [13]. While this condition is relatively uncommon, the reported coexistent incidence of endometrial cancer and an atrial myxoma is extremely rare. Consequently, the precise method in which to approach patient management can be very complicated for physicians [9].

In patients with an atrial myxoma, one of the primary concerns is the potential for a thromboembolic event. Embolism occurs in about $30-40 \%$ of patients, which may result in transient ischemic attack, stroke, or seizure [5, 8]. Endometrial adenocarcinoma patients are typically diagnosed with stage 1 disease, but the lesions can be more aggressive, and periodically are associated with metastases, lymphatic involvement and secondary conditions, such as a bowel obstruction [14]. The most common presenting symptom of endometrial cancer is vaginal bleeding, which interestingly was not reported by this patient.

In the present case study, the clinical decision was deliberated upon and corroborated with cardio-thoracic surgery consultation. The deciding factor in initially treating the endometrial cancer reflected the concern for a metastatic malignancy and the quiescent nature of the cardiac lesion. Moreover, prompt and aggressive treatment is a primary tenet in oncology standard of care [14].

In addition to the patient's very rare and complicated condition, the fact that she was also afflicted with metastases from a presumed primary lung cancer is noteworthy. Following gynecologic surgery, the patient was recovering without incident. Unfortunately, further postoperative imaging revealed brain metastases, presumably from the primary lung cancer. We suspect that this likely contributed to her intractable nausea, which persisted after resection of her mesenteric mass. The plan is for the patient to complete chemotherapy and brain radiation, at which point resection of her cardiac mass would be considered. However, because of the woman's advanced age, precarious medical condition, and stage 4 lung cancer, her long-term outcome is unfavorable.

There have been previously reported studies involving a uterine leiomyoma or leiomyosarcoma extending into or simulating an atrial myxoma $[10-12,15]$. Nevertheless, we were only able to identify one reported case documenting the treatment for both primary uterine cancer and an atrial myxoma [9]. Barlow et al. [9] described a patient who presented with a $2 \times 2-\mathrm{cm}$ polypoid myxoid uterine lesion. Frozen section revealed lack of nuclear atypia and mitotic activity, consistent with a benign, myxoid leiomyoma. Following further evaluation, the patient was diagnosed with a right $4-\mathrm{cm}$ intra-atrial myxoma. Due to the size of the cardiac lesion and the patient's reported episodic dizziness and syncope, the atrial myxoma was immediately resected. One month later, she was admitted for abdominal surgery to remove the uterine lesion.

Currently, the reported concurrent incidence of primary uterine cancer and an atrial myxoma is very rare. Therefore, reconciling the manner and order in which to treat these two diseases presents considerable clinical difficulty [9]. A physician team comprising gynecologic oncology, cardio-thoracic surgery and cardiology should collaborate in determining optimal patient management. Regrettably, even with prompt and comprehensive treatment, there is a significant risk for patient morbidity and mortality. 


\begin{tabular}{c|l|l|l}
$\begin{array}{c}\text { Cose Reports in } \\
\text { Oncelogy }\end{array}$ & $\begin{array}{l}\text { Case Rep Oncol 2009;2:150-156 } \\
\text { Dol: 10.1159/000231995 }\end{array}$ & & $\begin{array}{l}\text { Published online: August 20, 2009 S. Karger AG, Basel } \\
\text { ISSN 1662-6575 } \\
\text { www.karger.com/cro }\end{array}$ \\
\hline
\end{tabular}

\section{Acknowledgement}

This study was supported by a grant from the Women's Cancer Research Foundation.

Fig. 1. The atrial myxoma is seen as a large soft tissue mass arising from the left atrium and extending though the mitral valve into the lumen of the left ventricle.

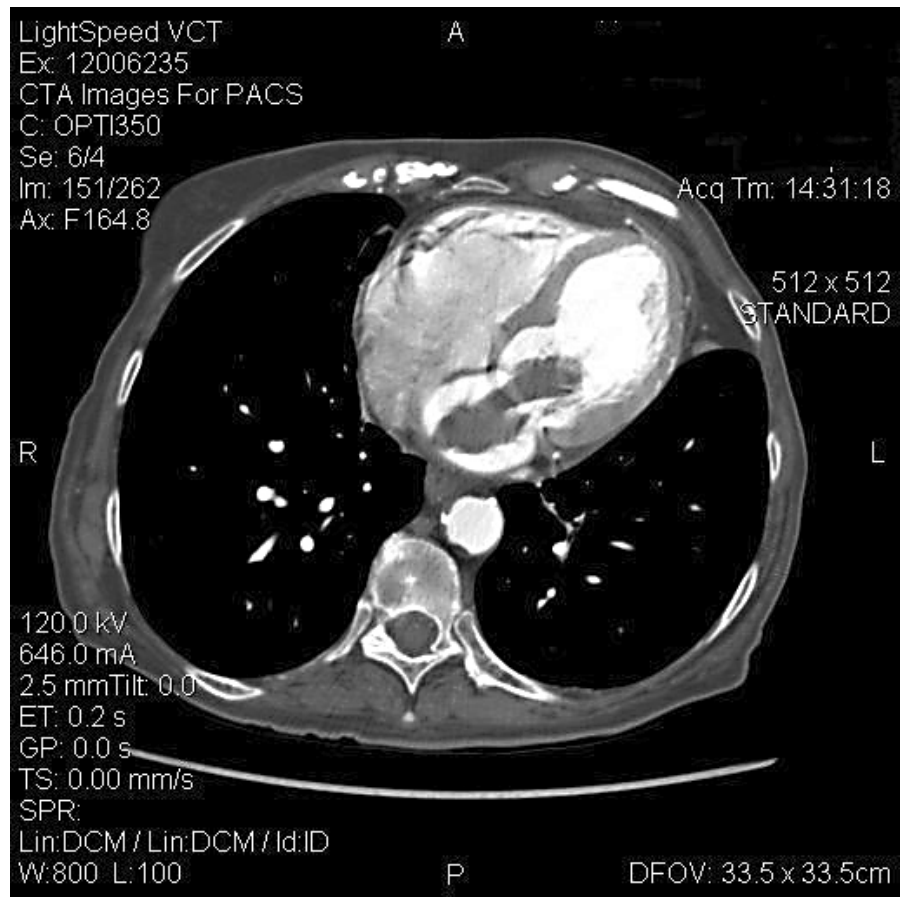




\begin{tabular}{c|l|l|l}
$\begin{array}{c}\text { Cose Reports in } \\
\text { Oncology }\end{array}$ & $\begin{array}{l}\text { Case Rep Oncol 2009;2:150-156 } \\
\text { D01: 10.1159/000231995 }\end{array}$ & & $\begin{array}{l}\text { Published online: August 20, 2009 S. Karger AG, Basel } \\
\text { ISSN 1662-6575 } \\
\text { www.karger.com/cro }\end{array}$ \\
\hline
\end{tabular}

Fig. 2. The endometrial tumor was low-grade and comprised glandular characteristics of endometrial carcinoma. The tumor was also positive for estrogen receptors and negative for carcinoembryonic antigen (CEA) and thyroid transcription factor (TTF-1, which is distinctively positive in lung adenocarcinomas and thyroid carcinomas).

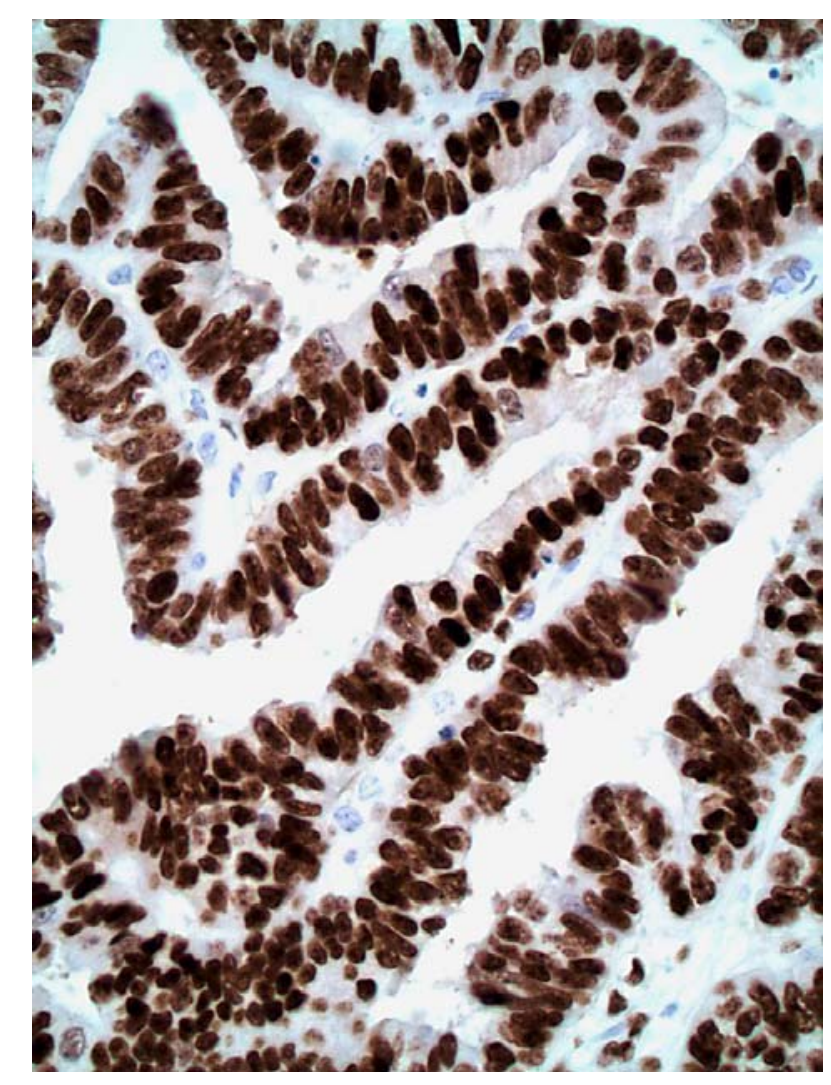




\begin{tabular}{c|l|l|l}
$\begin{array}{c}\text { Cose Reports in } \\
\text { Oncolady }\end{array}$ & $\begin{array}{l}\text { Case Rep Oncol 2009;2:150-156 } \\
\text { D0I: 10.1159/000231995 }\end{array}$ & Published online: August 20, 2009 & $\begin{array}{l}\text { O 2009 S. Karger AG, Basel } \\
\text { ISSN 1662-6575 } \\
\text { www.karger.com/cro }\end{array}$ \\
\hline
\end{tabular}

Fig. 3. The mesenteric tumor was high-grade, exhibited nerve infiltration, and formed sheets with necrosis. The tumor staining was negative for estrogen receptors, but positive for carcinoembryonic antigen (CEA) and thyroid transcription factor (TTF-1, characteristically positive in lung adenocarcinomas and thyroid carcinomas).

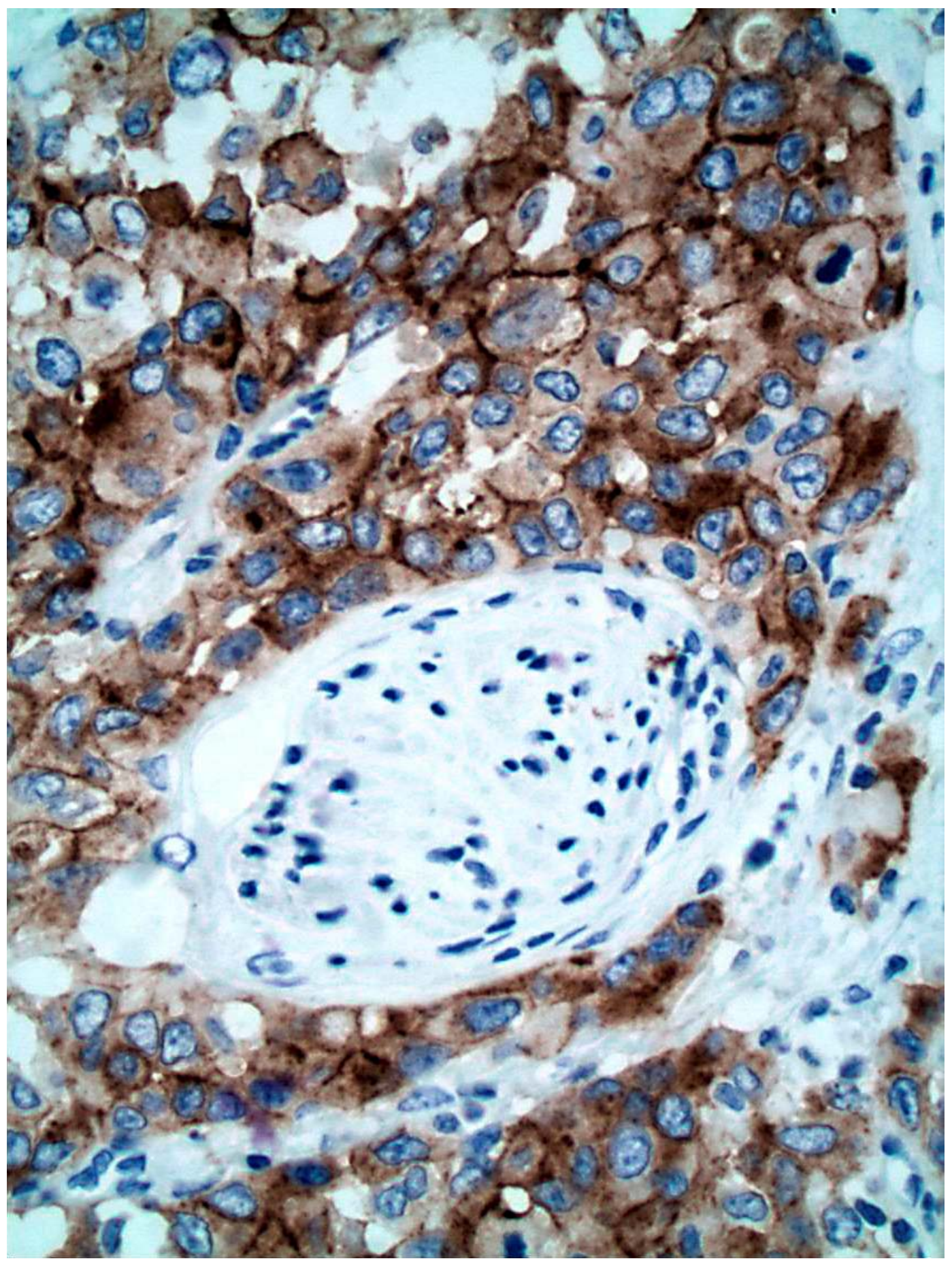




\section{References}

1 Yamada T, Hirose H, Umeda S, Murakawa S, Mori Y, Iwata H: Right ventricular myxoma - case report and review of the literature. Nippon Kyobu Geka Gakkai Zasshi 1993;41:1069-1073.

2 Amoah AGB, Frimpong-Boateng K, Kallen C, Barwasser HM: Atrial myxoma: a case report and review of the literature. WAJM 1988;17:50-54.

3 Rathore KS, Hussenbocus S, Stuklis R, Edwards J: Novel strategies for recurrent cardiac myxoma. Ann Thorac Surg 2008;85:2125-2126.

4 Lane GE, Kapples EJ, Thompson RC, Grinton SF, Finck SJ: Quiescent left atrial myxoma. Am Heart J 1994;127:1629-1631.

5 Aoyagi S, Tayama E, Yokokura Y, Yokokura H: Right atrial myxoma in a patient presenting with syncope. Cases J 2008;1:386.

6 Nakamura K, Asai T, Murakami M, Saito Y, Yoshimoto A, Yamaguchi H: Giant right atrial myxoma associated with tricuspid regurgitation. Jpn J Thorac Cardiovasc Surg 2006;54:332-334.

7 Levy S: Atrial fibrillation, the arrhythmia of the elderly, causes and associated conditions. Anadolu Kardiyol Derg 2002;2:55-60.

8 Ojji DB, Ajiduku SS, Omonua OO, Abdulkareem LL, Parsonage W: A probable right atrial myxoma prolapsing through the tricuspid valve into the right ventricle: a case report. Cases J 2008;1:386.

9 Barlow JF, Abu-Gazeleh S, Tam GE, Wirtz PS, Ofstein LC, O’Brien CP, Woods GL, Drymalski WG: Myxoid tumor of the uterus and right atrial myxomas. S D J Med 1983;36:9-13.

10 Glazer M, Kioscos JM, Kroetz FW, Lawrence MS, Korns ME: Simulation of right atrial myxoma by metastatic leiomyosarcoma. Cancer 1970;27:238-241.

11 Tamburino C, Russo G, Incognito C, Battaglia G, Monaca V, Lomeo A, Abbate M: Intracardiac extension of a calcified ovarian hemangioma - a case report. Angiology 1992;43:249-252.

12 Lang RM, Borow KM, Neumann A: Metastatic carcinoma involving the left atrium. Am Heart J 1985;110:884-886.

13 American Cancer Society Cancer Facts and Figures 2008. Atlanta, GA, American Cancer Society, 2008.

14 Morrow CP, Curtin JP: Synopsis of Gynecologic Oncology. Pennsylvania, Churchill Livingstone, 1988.

15 Kaszar-Seibert DJ, Gauvin GP, Rogoff PA, Vittimberga FJ, Margolis S, Hilgenberg $\mathrm{AD}$, Saal DK, Goldsmith GO: Intracardiac extension of intravenous leiomyomatosis. Radiology 1988;168:409-410. 